\title{
Institutional Culture \& Academic Entrepreneurship Averting a Crisis and Salvaging the Last Bastion of Competitiveness
}

\author{
Vijay Srinivas \\ Doctoral student, School of Information Studies, Syracuse University, Syracuse, NY 13244, USA \\ srinivas@syr.edu
}

\begin{abstract}
Federal research fundingfor universities (chiefly, NSF, NIH, DOD,DOE) stands at a staggering 30 billion dollars or so, and there is an increasinglevel ofquestioningandscrutinyastothe'returnoninvestment 'for suchdollars,intermsofsocietaleconomicimpactbothwithin the funding agencies and by our elected representatives.Figuring out ways to foster and sustain academic entrepreneurship (industry engagement; licensingof IP; launching start-ups) may be the way to take advantage of industry funding for research,whilealso ensuring that research of anappliednature(particularlyinengineeringprograms) can directly solve industry problems and thussupport the creation of jobs.
\end{abstract}

Thirty years after the Bayh - Dole Act-meant to encourage academic entrepreneurship, we find ourselves where university-industry interaction is still not pervasive. The proposed research is predicated on the notion that organizational culture (policies, processes, beliefs, and attitudes) have a significant influence on academic entre preneurship. An understanding of the institutional culture and how it correlates to entrepreneurial activities of faculty canthus be instructive and helpful. The proposed study aims to identify and understand this.

\footnotetext{
Vijay Srinivas

Doctoral student, School of Information

Studies, Syracuse University, Syracuse, NY 13244, USA

srinivas@syr.edu
}

The proposed research is guided byinitial insights obtained from a small set of (6 faculty)open-ended interviews that were conducted as pilot data collection. Thiswascomplemented by an autoethnographic examination ofuniversity culture, carried out over the course of a semester to examine university-industry interactions. Data collection via adesigned survey instrument is being proposed as the means forobtainingthe data for subsequent analysis andinterpretation.

Understanding the drivers (institutional culture) of academic entrepreneurship and the measures of an entrepreneurial culture can, in the long-run, play a pivotal part in universities embracing their 3rd mission - that of economic impact and industry development (the first 2 missions being teaching and research).

Keywords:Academic entrepreneurship, institutional culture, third mission, ROI,start-ups, universityindustry engagement.

\section{Introduction}

It was not long ago, that US was considered to be the leading nation in research and development - far above the rest of the world. Research and development was well funded and companies like Bell Labs, IBM, GE, GM, and others invested significantly into research and development. Then with the federal government investing in research at US universities via the formation of the NSF 
(Vannevar, 1945), there began a gradual shift in industrial research -in the United States, as companies began to depend on universities to carry out basic or fundamental research. The research base in companies saw steady erosion over the next several decades. The 'externalization of research' in industry began in the 1980s, (Mowery, 1998) largely due to competitive price pressure, and large corporate research facilities of pioneers of industrial R\&D such as General Electric, AT\&T, and DuPont began sharply reducing in size, and utilizing alternative arrangements such as consortia, alliances, and university partnerships to meet their basic research needs. US universities taking on a more central role in the nation's innovation system, in the last several decades by doing a bigger share of the basic research, as companies such as Bell labs began to focus on developmental activities and away from basic R\&D (Atkinson and Stewart, 2011).

Declining federal funding for research at universities and other cuts (as evidenced by the recent DOD sequestrations) has resulted in an untenable situation for the research base of the nation. With little or no research being conducted within companies, and reduced (or reducing) federal spending on research being the new normal, it bodes badly for our nation's competitiveness. I assert that this is a crisis for the nation, but I also add that this is an opportunity for universities to engagewith industry and seek industry funding for research that supports industry needs. Academic entrepreneurship can thus help avert this crisis and help in maintaining our nation's industrial competitive advantage.

Companies are looking for research capacity; universities are looking for funding to offset the federal cut-backs - academic entrepreneurship could provide the path for continued funding for university research, while also fulfilling industrial research - a win-win for all. The importance of understanding academic entrepreneurship and in removing barriers and impediments so as to facilitate such entrepreneurial activities is both timely and vitally important.

Higher education in the U.S. has come under increasing scrutiny and criticism by many of its stakeholders. The ever escalating cost, coupled with how universities find themselves relevant (or irrelevant) in today's marketplace, is precipitating a query of the traditional way of how universities have conducted themselves. Universities have a responsibility to serve the 'public good' (Calhoun, 2006) and (Etzkowitz, 2000) - for after all, a significant source of research funding for universities is derived from the taxpayer.

The scale of federal funding for research at US universities is significant and there is increasing emphasis by the funding agencies to ensure that such funded research results in economic activity and impact. The US Congress commissioned study, National Research Council (2014) examines the 'ROI' of the federal research investment in the nation and concludes that the measures of such ROI are difficult to get at, and that the current measures are not adequate for to properly characterize the complex research system that we have, here in the US, at our universities. What is unequivocal, however, is the quest to seek and maximize such a return on investment for the nation's research dollars.

Federally funded academic R\&D expenditure in US universities is estimated to be at $\$ 30.4$ Billion in 2007, and the total R\&D expenditures (federal and non-federal) at nearly $\$ 50$ Billion in that same year (Britt, 2008). While there can be debate as to whether these numbers represent the 'right' proportion of the US GDP being invested in research, or whether this amount has risen appropriately over the years - there can be no debate that these are non-trivial dollar investments, by any standard and that when compared to operating budgets of individual universities (on the scale of a billion dollars), these numbers are indeed significant. It is also easy to appreciate that there is an increasing expectation that such funding will result in the creation of new industry (via technology transfer and monetization) and in jobs and economic development. This has resulted in federal agencies (like the National Science Foundation (NSF)) looking for university researchers to pay attention to university-industry engagement and collaboration and in research having an "applied" slant. The NSF programs like the ERC (Engineering Research Center) place heavy emphasis on industry engagement to help identify real-world challenge problems that the ERC can help solve. The NSF ICorp program is aimed at translational work to help evaluate (and transition) technologies developed at the university (using NSF funds) to market.

The role of faculty in engaging with industry is central to academic entrepreneurship. "Faculty as entrepreneur" is key to such meaningful and successful engagement with industry and in research 
that creates utility for the real-world. Faculty's ability to balance the many competing demands on their time and bandwidth and in dealing with the often opposing paradigms and cultures - the individualistic, tenuredriven paradigm of academia, with the collaborative, 'team-first', market economics-driven culture of companies is key to understanding what drives faculty entrepreneurship and how best to harness this latent force - for this could be the key to defending America's last bastion of innovativeness and hence its competitive advantage.

Understanding the academic entrepreneur is thus timely and almost a necessity to help attain a better return on the research investments made using taxpayer dollars in universities by ensuring that such investments result in job and industry creation and economic development. The role of the US University in economy building is clarified as a core driver of technological innovation and as being in an evolving role in economic development. Also pointed out, is the current acute need for university-industry interaction in this context (Atkinson and Pelfrey, 2010).

\section{Motivation For This Study}

The role of the contemporary university and societal expectations of it are changing to now additionally support entrepreneurship, and this in turn entails a certain cultural mindset of the university with associated processes and structure. Universities are undergoing a "second academic revolution," and incorporating economic development as part of their mission (Etzkowitz et al, 1998) and (Powers and McDougall, 2005). The universities' first revolution was to incorporate research as a core function of the enterprise. The impact of "organizational resources" in performing the additional scope of economic development to a university's mission is examined in detail (Etzkowitz, et al, 1998). The relationship between industry $\mathrm{R} \& \mathrm{D}$ and university culture is described as being "less obvious" and as not being fully explored (Powers and McDougall, 2005). The university's emerging mission of "economic development", in addition to teaching and research often results in 'conflict issues and points of friction' within a university when pursuing this new mission. University faculty and administrators require new skills and abilities in order to deal with industry partners (as part of the economic development mission) and institutionally new values and strategies may need to be incorporated- as part of the fabric of the university's culture (Laukkanen, 2003).
University management systems (and processes) historically designed to address teaching and research activities are not really suitable for activities relating to academic entrepreneurship. It is identified that coordination among the various functional groups and faculty, in support of academic entrepreneurship may be influenced by the institutional structures of universities (Wright et al, 2009). I interpret this to be an aspect of the university culture - values, beliefs, structure and processes. The issue of understanding the influence of institutional structure, and culture (my term) is largely not addressed in extant literature (Wright et al, 2009).

\section{Research Questions Addressed In The Study}

This study focuses on academic entrepreneurship and seeks to identify institutional factors that foster entrepreneurial activity. Organizational culture at the university and its impact on academic entrepreneurship is examined in this study. Institutional factors that influence (or impede) academic entrepreneurship will be identified and examined. In looking to understand the motivational drivers and associated aspects for faculty to engage in entrepreneurial activities and attain success in it, the study will identify barriers that faculty have encountered in their entrepreneurial activities and (their motivation) to overcome the same.

The following research questions help frame my overall query and approach to data collection:

Descriptive Research Question - The 'What' Question:

What are the factors (organizational culture related, as well as individual-related) that contribute to a faculty being entrepreneurial? (Exploratory descriptive question)

What barriers are identified by faculty as impediments in their entrepreneurial quest?

Inferential Research Question - The 'How' Question:

How does a particular attribute foster faculty being more entrepreneurial and having commercial success in the context of their research?

How is faculty motivated to work around the barriers and in being entrepreneurial?

How entrepreneurial culture is best identified and measured?

Causal Research Question - The 'Why' Question:

Why certain faculty attain success in launching 
start-ups, and in entrepreneurial success via monetizing their research findings?

The purpose of this study is to identify and understand the factors (primarily institutional factors including culture) that can influence (or impede) academic entrepreneurship. Knowledge of the factors and their influence (impact), can help propose changes to policies, procedures, and attitudes on campus to foster successful academic entrepreneurship on campus. To the extent that the study discovers individual traits and aptitudes that are best aligned with academic entrepreneurship, this can be factored into the process of new hires to the institution. The study is a systematic collection of data to uncover correlates between the factors that influence academic entrepreneurship and the resulting success of such academic entrepreneurial activities. It is also envisioned that uncovering the factors (cultural) will help understand the 'entrepreneurial culture' and in identifying measures for this.

This study is focused on uncovering key practices, organizational structures, policies, processes, and institutional attitudes (as part of the overall culture) that impact and influence academic entrepreneurship. The study aims to uncover factors that facilitate as well as those that impede academic entrepreneurship and in understanding and identifying the measures of 'entrepreneurial culture'.

\section{A. Definitions}

For the purposes of my study I will operationalize the broader definition of academic entrepreneurship, in my study as entrepreneurial action (on the part of faculty) to comprise:

( Engaging in university-industry partnerships, and being a recipient of corporate sponsored research

u Technology translational activities, i.e. creation of, protection of, and licensing of university IP

Q Launching start-ups and new ventures (including participation in SBIR opportunities)

Similarly my preliminary definition for entrepreneurial success is: multi-year corporate sponsored research; existence of start-up after 3 years of its launch; licensing of technology that has resulted in licensing revenue within $2-5$ years after such license, and with such licensing revenue being derived for 2 or more years.

\section{B. Biases}

It is important to point out that my role as an employee of Syracuse University and in particular as the Senior Director of Corporate Relations and Technical Alliances at the university provides me with a certain unique viewpoint in this study. My functional role at the university is to help facilitate universityindustry partnerships via sponsored research engagements and broadly in helping faculty intellectual property through translational and commercialization opportunities with industry partners. I have functioned in this role for about 4years. Prior to this I worked in industry for nearly 20 years in various systems engineering and business development capacities. This autoethnographic viewpoint provides me with a way to use my (the researcher's) experiential knowledge and in being able to examine my interactions with the various offices and functions in the context of academic entrepreneurial activities - but can also likely introduce biases. I recognize that my industry experience will likely introduce a tone of comparing industry and university organizational settings, in my interpretations of the organizational culture at the university. In my functional role at the university, I often see myself in various self-ascribed capacities of an evangelist, or change agent, or activist during my various interchanges with functional groups in the context of academic entrepreneurial activities. Care will need to be taken to ensure that biases (introduced by me as the researcher) associated with the interpretations continue to be identified and called out in the final analyses.

\section{Data Collected Via Pilot Studies}

\section{A. Pilot Interviews}

A pilot set of interviews was conducted to obtain preliminary insight into faculty aptitude for entrepreneurial motivation. A purposive sample (nonprobability), a non- representative subset of the larger faculty population at Syracuse University, was used and was constructed to serve this very specific purpose. I selected a specific group of faculty that met the definitional framework that I employed for this study (as stated earlier). Using such definitional criteria, I then worked with the Office of Sponsored Programs to identify faculty that best met such criteria. As part of my purposive sampling, I also (or 
utilized the snowball technique in identifying my sample by asking participants (or office of Research and Office of Technology Transfer) to suggest others who might be appropriate for the study, and who were willing to participate. A total of six faculty were identified and interviewed via the following guiding questions:

1. Help me understand your "entrepreneurial" journey. How did you get started?

2. What key barriers and challenges have you encountered in this journey? Please elaborate with examples. Can you classify the barriers into categories (for ex. Structural, process, access, etc.?)

3. What motivates you to be "entrepreneurial" - How did you derive the energy to overcome your barriers and challenges

\section{Outcomes of Pilot Interviews:}

The interviews helped uncover some initial patterns and trends - both with respect to what allows for a faculty member to be successful in academic entrepreneurship, as well as in identifying some common challenges and issues that faculty have run into - when it comes to academic entrepreneurship. Noting that all faculty that were interviewed as part of this pilot study met the criteria of either having been part of start-ups, and/or involved in projects with industry, and/or had created IP that was then licensed outside of the university, it is to be pointed out that all of the interviewees possibly had some aptitude and inclination toward being entrepreneurial. Notwithstanding this, it is to be noted that every one of the interviewees, except one spoke at length on the challenges and barriers that they had faced in their entrepreneurial pursuits.

Some key insights gathered:

口 Faculty as the 'creative or idea person' could benefit from infrastructure that seamlessly takes over the idea for scale-up and market introduction, so that faculty can focus on what they do best - i.e. be creative and produce new ideas

o The traditional organization and model of the university is set up to preserve and support teaching and research. The measures used, while not being very transparent and clear at times, are also in support of these traditional goals. Entrepreneurial activities are neither measured, nor valued in the traditional framework of values and thinking within the university

u The TTOs are set up to deal with the creation, protection, and to a lesser extent the monetization of IP created by faculty - particularly in the post BayhDole Act era. Such offices and mechanisms to facilitate commercialization of IP that do not lend themselves to being patented and hence protected in the traditional manner

( The practice of awarding tenure (central to academia, in its current form) is a disincentive - as there is no 'pivot' from tenure Institutionally, encouraging (or perhaps even make standard) faculty to take sabbaticals to spend in industry, or even better spend as part of a start-up would help introduce entrepreneurial thinking i.e. rethinking the processes and policies on an institutional basis

( Time and funding - two scarce commodities for faculty can seriously come in the way of being entrepreneurial

口 Provide support to faculty via IP landscape studies, market research, and patent due diligence - as these will alleviate pressures for faculty to entertain and pursue entrepreneurial activities, i.e. make available resources...

Q Greater awareness, appreciation, and acceptance (especially in engineering - an applied science) of the Gordian knot between applied and fundamental research

( Deans and academic heads - and their view of entrepreneurial faculty - often such faculty are not applauded or even acknowledged - this makes it harder for acceptance by peers and certainly does not position entrepreneurial activity as something to aspire for

૫ To foster entrepreneurial thinking and activity, institutionally there is a need for research infrastructure; cadre of systems and staff engineers (to offset capacity imbalances); business mentoring

o Leadership at all levels must embody a culture of celebrating and recognizing faculty's entrepreneurial activities and accomplishments; widely disseminate and promote the accomplishments - so it is common knowledge 
( Rewards and incentives to promote entrepreneurial engagement and associated activities

口 Make processes and policies transparent; remove institutional barriers

\section{B. Autoethnography}

An autoethnographic study was carried out to examine aspects organizational culture at Syracuse University as it intersects and impacts academic entrepreneurial activities. Autoethnography is a research method that allows the author to write in a highly personalized style, drawing on his or her experience to extend understanding about a societal phenomenon with reflexivity (Wall, 2008). The genre of qualitative research inquiry has built into it an inextricable link between the personal (of the researcher) and the cultural environment that is being studied. Autoethnography should be ethnographical in its methodological orientation, cultural in its interpretive orientation, and autobiographical in its content orientation (Chang, 2008). In this study, given my role in the corporate relations function, I engaged as a participant in the overall process of academic entrepreneurship and as such examining the content from an autobiographical and participant observant viewpoint. I seek to understand and interpret the university culture and associated processes and structures, by adopting an interpretive orientation. In studying the organizational culture, decision-making, behaviors and attitudes as exhibited by the institution as an entity, I employed ethnography as my qualitative method of inquiry.

1) Research Question(s): What are the processes of entrepreneurial scholarship at SU? What is the organizational structure at $\mathrm{SU}$, and the organizational culture and how does it intersect and/or influence academic entrepreneurship at SU? How do structure, processes, and cultural attitudes affect the university's abilities to engage with corporate partners?

2) Scope of study: The study is aimed at gaining understanding of the prevalent culture and attitudes at an institutional level at Syracuse University with respect to functions and activities that pertain to academic entrepreneurship. The study does not focus on individuals as the unit of analysis; instead it abstracts aspects of organizational culture at an institutional level (a systems level analysis) with a view to understanding the impact and influence of organizational culture on entrepreneurial activities at the university. Key functions that are typically engaged with respect to academic entrepreneurship are the offices of Research, Sponsored Programs, Technology Transfer, Corporate Relations and many of the University Research Centers. This study captures key interactions across these functions as they relate to academic entrepreneurship.

The paradigms of academia and industry have traditionally been quite different and often nonintersecting. Identifying that the interface, if university-industry partnerships are to be successful, requires to satisfy both the university and industry characteristics, points to adaptations and changes by both parties in order to have a functioning interface. I have always believed that the concept of the 3 E's of an EntErprisE - Efficiency, Economy, and Efficacy are an integral part of the industry paradigm. Industry strives to adopt role-based division of labor to increase efficiency, and functions and processes are set up to take advantage of economies of scale and scope, and finally, efficacy is measured via metrics and improvements made via the feedback function. Such an industry paradigm is supported by unity in purpose and in the organization working together as an entity and the overall objective function of the organization being optimized. The university on the other hand is organized as a loose federation of schools and colleges and there is much autonomy provided to the individual units.

Aspects of organizational culture that were examined as part of the autoethnography include, university-industry partnerships; launching of startups and new ventures; and the licensing of university IP. Summarized in the next section is key findings from an autoethnographic examination of universityindustry partnerships.

\section{University-Industry Partnerships:}

There are no processes that guide how universityindustry partnerships are to be initiated and managed. Each individual faculty member can reach out to industry and create one's own relationships. Such relationships are not centrally tracked, nor managed. Faculty is not required to include Corporate Relations in their interactions with companies. This is not necessarily due to faculty "behaving badly", but it is fundamental to faculty having the autonomy to pursue things as they find interesting. This culture of individualism, thus completely obviates the economies of scale and scope that a large enterprise 
(like the university) should take advantage of. The individualistic practices also don't take advantage of role specialization as prescribed by Fredrick Taylor, (McLeod, 1983). Taylor's view of division of labor allows enterprises to have the advantages of economies of scale and scope and to leverage the $3 \mathrm{E}$ 's, viz., Economy, Efficiency, and Efficacy. For example, instead of entrusting functional groups to have responsibility for tasks with a certain specialization, the individualistic culture that is supported at the university results in faculty individually engaged in 'business development' tasks and not allowing a specialized function to carry it out instead. This individualistic culture, thus not only results in diseconomies, but also presents an opportunity cost (i.e. the time spent by faculty in individualistic corporate engagement, instead could be better spent on pursuing research) to the institution. There is no accounting mechanism to track such costs to the institution. Another inherent inefficiency that is built into individualistic behavior is that multiple faculty end up interacting with the same company, and there is no mechanism to centrally manage the relationship and seek holistic optimization of the relationship at the institutional level vis-à-vis, sub-optimizing at the individual level. So we see that the individualistic culture embodied in faculty, in opposition to enterprise economies and efficiencies that the institution as a whole should be leveraging by virtue of being a large enterprise. Viewing this in the framework of organizational culture, it appears that there is no mechanism or penalty for bad decisions at the institution which may support the prevalent behavior in how the university approaches industryuniversity relationships (Tierney, 1988).

Some perspective from the industry viewpoint will help understand the interface boundary between industry and university. In my interactions and associated conversations with university liaison persons at a couple of large corporations, I learned that corporations see the need for a single point of contact that has the ability to speak for and commit on behalf of the university in such partnerships. They add that corporations prefer not to have to work just with individual faculty members, but that they prefer to work with a group in order to take advantage of the diversity in thought, as well as the synergy that can result from members of that group collaborating and working collectively on the company's projects.

\section{Next Steps -Full Study Approach}

Depending on the level of analysis and unit of analysis I wish to examine in my study - individual unit of analysis or institutional unit of analysis, there could be different approaches. Culture being a collective phenomenon, querying an individual about institutional culture will only elicit that individual's perception of culture. An approach would be to have an institutional spokesperson to inform us on culture of the institution - noting that there clearly is selfreporting bias, and this is still one person's interpretation (perception) of institutional culture. An in-depth case study could be another approach to understand the influence of institutional culture on $\mathrm{AE}$, at the institution being studied - but this does not readily lend itself to generalizable findings.

\section{Approach 1}

In order to measure the collective sentiment of the population, I would choose say, 3 universities along a continuum of how successful they are at being entrepreneurial (AE performance) - picking one university at the low end, one in the middle, and another at the higher end.

At each of these universities, in order to minimize within- sample variance, I would pick a homogenous sample of faculty- say engineering faculty and survey that sample. Using the mean values of observations (from survey) for each of the universities, one could perform a comparison to see if there are indeed differences between the means of the populations from the 3 universities - this could allow us to make some inferences, at an institutional unit of analysis, on the influence of culture on AE.

In addition to surveying the faculty to get their input regarding "institutional culture", we could also poll a representative for the institution (as a surrogate for the entire organization), such as VPR, to get data on institutional culture.

One could possibly pick SU and a couple of its peers using IPEDS dataset for this approach.

\section{Approach 2}

In carrying out the examination at an individual unit of analysis, the following approach may be considered.Identify a sample of convenience, of entrepreneurial faculty across several universities. This may be accomplished, say by using the list of all faculty that have participated in the NSF I- Corp program, and/or faculty that have had success in level 
commercializing IP and launched start-ups. Such a list is probably available via the Kauffman Institute of Entrepreneurship. Survey this group of faculty to understand their level of entrepreneurial activity and their corresponding level of barriers and impediments faced. Plotting this should uncover a negatively correlated regression cluster (higher the level of AE success, lower the impediments/barriers and vice versa). From such a regression plot, it may be possible to infer that certain elements (barriers) of institutional culture can influence AE effectiveness.

The dependent variable (DV) could be a composite measure along the lines of:

\section{a. Engaging with industry in sponsored projects}

b. Revenues generated by faculty created, universityowned IP licensed by outside entities for commercialization

c. Start-ups and new ventures resulting from IP or technology created by faculty

Exemplar independent variables (IV) could comprise:

a. Faculty Demographics: Information regarding seniority level of faculty

b. Institutional support/commitment: captured along several facets, such as messaging, leadership, resources allocated, administrative support etc.

\section{c. Experiential and other learning}

d. Personality traits Institutional culture as embodied in the values espoused, attitudes of functions and staff, processes adhered to, and the policies used to govern

\section{e. Student/ecosystem that exists on campus}

A conceptual model similar to that of entrepreneurial intentions, (Prodan\& Drnovsek, 2010), and use of factors and attributes similar to those in the ENTRE-U model, (Todorovic et al 2011), will be employed in constructing the survey instrument to collect data and to look for patterns and correlations.

\section{Concluding Thoughts}

The very nature of institutional culture that makes it difficult to identify and describe and understand is also the same attribute of an institution that can powerfully shape and influence the behavior and performance of the entity and its people. It is the contention of thiswork thatan understanding of institutional culture in its constituent parts and relating it to faculty inclination and success in entrepreneurial activities will allow for universities to effectively fulfill their 3rd mission - that of economic development. Universities embracing their 3rd mission could have a transformative effect in technology innovation and its commercialization. The findings when this study is completed will help address and possibly validate the notional premise on which this work is being carried out.

\section{References}

Vannevar, B., (Dec., 1945). Science: The Endless Frontier, Transactions of the Kansas Academy of Science (1903-), Vol. 48, No. 3, pp. 231-264, $\mathrm{K}$ an s a s A c a d e m y of S c i e n c e, S ource : http://www.jstor.org/stable/3625196

Mowery, D. C. (1998). The changing structure of the US national innovation system: implications for international conflict and cooperation in R\&D policy. Research Policy, 27(6), 639-654.

Atkinson, R. D., \& Stewart, L. A. (2011). University Research Funding: The United States Is Behind and Falling. Information Technology and Innovation Foundation.

Calhoun, C (2006). The university and the public good. Thesis Eleven, 84 (1). pp. 7-43. ISSN $0725-$ 5136.

Etzkowitz, H., et al. (2000). "The future of the university and the university of the future: evolution of ivory tower to entrepreneurial paradigm." Research Policy 29(2): 313-330.

Britt, R. (2008). Universities report continued decline in real federal S\&E R\&D funding in FY 2007. Info Brief. NSF 08-320. Arlington, VA: National Science Foundation. Retrieved Aug 31, 2013 from: http://www.nsf.gov/statistics/infbrief/nsf08320/nsf0 8320.pdf

Atkinson, R.C., and Pelfrey, P.A., (2010). SCIENCE AND THE ENTREPRENEURIAL UNIVERSITY. UC Berkeley: Center for Studies in Higher Education. $\begin{array}{lllllllllllllll}R & e & t & r & i & e & v & e & d & f & r & o & m & \text { : }\end{array}$ http://escholarship.org/uc/item/0q01n64

Etzkowitz, H., Webster, A., Healey, P., 1998. Capitalizing Knowledge: New Intersections of Industry and Academia. State Univ. of New York, Albany.

Powers, J. B., \& McDougall, P. P. (2005). University start-up formation and technology licensing with firms that go public: a resource-based view of academic entrepreneurship. Journal of Business Venturing, 20(3), 291-311. 
Laukkanen, M. (2003). Exploring academic entrepreneurship: drivers and tensions of universitybased business. Journal of Small Business and Enterprise Development, 10(4), 372-382.

Wright, M., Piva, E., Mosey, S., \& Lockett, A. (2009). Academic entrepreneurship and business schools. The Journal of Technology Transfer, 34(6), 560-587

Wall, S. (2008). An autoethnography on learning about autoethnography. International Journal of Qualitative Methods, 5(2), 146-160.

Chang, H. (2008). Autoethnography as method. WalnutCreek, CA: Left Coast Press.

McLeod, M. (1983). "Architecture or Revolution":
Taylorism, Technocracy, and Social Change. Art Journal, 132-147.

Tierney, W. G. (1988). Organizational culture in higher education: Defining the essentials. The Journal of Higher Education, 2-21.

Prodan, I., \& Drnovsek, M. (2010). Conceptualizing academic- entrepreneurial intentions: An empirical test. Technovation, 30(5), 332-347.

William Todorovic, Z., McNaughton, R. B., \& Guild, P. (2011). ENTRE-U: An entrepreneurial orientation scale for universities. Technovation, 31(2), 128-137. 